\title{
Screening Tests for Hypercortisolism in Patients With Adrenal Incidentaloma
}

\author{
Lia Ferreira ${ }^{\mathrm{a}, \mathrm{c}}$, Jose Carlos Oliveira ${ }^{\mathrm{b}}$, Isabel Palma ${ }^{\mathrm{a}}$
}

\begin{abstract}
Background: To compare the diagnostic performance of different first-line screening tests for subclinical hypercortisolism $(\mathrm{SH})$ in patients with adrenal incidentaloma (AI).

Methods: We studied a series of patients with AI, with no clinical evidence of hormonal hypersecretion. For screening for SH, all patients performed 1-mg dexamethasone suppression test (1-mg DST), late night salivary cortisol (LNSC) and 24-h urinary free cortisol (UFC). A control group of patients with confirmed Cushing's syndrome (CS) was used to calculate the diagnostic performance of the screening tests.
\end{abstract}

Results: In the 83 patients with AI, morning cortisol after 1-mg DST was $\leq 1.8 \mu \mathrm{g} / \mathrm{dL}$ in $69.9 \%, 1.9$ to $5 \mu \mathrm{g} / \mathrm{dL}$ in $26.5 \%$ and $>$ $5 \mu \mathrm{g} / \mathrm{dL}$ in $3.6 \%$. LNSC was elevated in $20.5 \%$ and all patients had normal UFC levels. In the control group, composed of 50 patients with confirmed CS, all patients who underwent 1-mg DST had cortisol levels $>1.8 \mu \mathrm{g} / \mathrm{dL}(1.9$ to $5 \mu \mathrm{g} / \mathrm{dL}$ in $16.2 \%$ and $>5$ $\mu \mathrm{g} / \mathrm{dL}$ in $83.3 \%$ ); LNSC was elevated in $93.8 \%$ and the UFC was increased in $85.4 \%$ of patients tested. Overall, for the screening of $\mathrm{SH}$, the 1-mg DST presented a sensitivity and specificity of $100 \%$ and $69.9 \%$ with its lowest threshold $(\leq 1.8 \mu \mathrm{g} / \mathrm{dL})$ and $83.3 \%$ and $96.4 \%$ with its highest threshold $(<5 \mu \mathrm{g} / \mathrm{dL})$. LNSC showed a sensitivity and specificity of $93.8 \%$ and $79.5 \%$ and the UFC of $85.4 \%$ and $100 \%$, respectively.

Conclusions: The 1-mg DST at its lowest threshold presented the highest sensitivity in identifying $\mathrm{SH}$, but its low specificity encourages us to consider UFC levels, to reduce false-positive test results.

Keywords: Adrenal incidentaloma; Hypercortisolism, Dexamethasone; Salivary cortisol

Manuscript submitted April 25, 2018, accepted May 7, 2018

aDepartment of Endocrinology, Centro Hospitalar do Porto, Largo Prof. Abel Salazar, 4099-001, Porto, Portugal

bDepartment of Clinical Pathology, Centro Hospitalar do Porto, Largo Prof. Abel Salazar, 4099-001, Porto, Portugal

${ }^{\mathrm{c} C}$ Corresponding Author: Lia Ferreira, Department of Endocrinology, Centro Hospitalar do Porto, Largo Prof. Abel Salazar, 4099-001, Porto, Portugal. Email: liaferreira00@gmail.com

doi: https://doi.org/10.14740/jem510w

\section{Introduction}

The widespread use of high resolution abdominal imaging procedures has led to an increasing prevalence of incidentally discovered adrenal masses [1,2]. The majority of adrenal incidentalomas (AI) are clinically non-functioning, benign adrenocortical adenomas [3]. Even in the absence of overt Cushing's syndrome (CS), 5 to $30 \%$ of patients with AI present abnormalities of hypothalamic-pituitary-adrenal (HPA) axis and exhibit various patterns of autonomous cortisol production, suggesting the existence of different degrees of subclinical hypercortisolism (SH) [4-6].

The diagnosis of $\mathrm{SH}$ is important because although these patients do not present the typical stigmata of CS, they are exposed to the long-term consequences of continuous, endogenous cortisol secretion, and frequently display features of metabolic syndrome, such as hypertension, obesity, diabetes mellitus, and osteoporosis [5, 7-9].

The prevalence of SH varies from 5 to $20 \%$ among patients with AI, depending on diagnostic criteria used to define it [10-14]. The lack of a golden standard makes the diagnosis of subclinical hypercortisolism difficult. Previous studies have used different diagnostic algorithms to exclude $\mathrm{SH}$, but a direct comparison between screening tests to evaluate their diagnostic accuracy has been scarcely studied [15].

The purpose of this study was to compare the diagnostic performance of different first-line screening tests to hypercortisolism in patients with AI.

\section{Patients and Methods}

To calculate the diagnostic performance of the screening tests for hypercortisolism, we performed a case-control study and compare patients with adrenal incidentaloma with a reference group of patients with confirmed CS.

\section{Group 1 (AI patients)}

From January 2015 to December 2017, 83 consecutive patients with adrenal incidentaloma referred to an endocrinology appointment in Centro Hospital do Porto were enrolled in the study.

The diagnosis of AI was based on the finding of an adrenal 
Table 1. Clinical and Biochemical Characteristics of Patients With Adrenal Incidentaloma

\begin{tabular}{|c|c|c|c|}
\hline & Unilateral adenoma & Bilateral adenoma & $\mathbf{P}$ \\
\hline Age (years) ${ }^{\mathrm{a}}$ & $66.9 \pm 13.9$ & $63.5 \pm 8.0$ & 0.406 \\
\hline Gender (N, \% female) & $45 / 63(71.4 \%)$ & $7 / 20(35.0 \%)$ & $<0.001^{*}$ \\
\hline Cortisol after 1-mg DST ( $\mu \mathrm{g} / \mathrm{dL})$ & $1.6(0.4-7.0)$ & $1.4(0.6-2.3)$ & 0.216 \\
\hline $\operatorname{LNSC}(\mu \mathrm{g} / \mathrm{dL})^{\mathrm{b}}$ & $0.206(0.005-1.140)$ & $0.296(0.050-0.621)$ & $0.019 *$ \\
\hline Obesity (BMI $\geq 30)(\mathrm{N}, \%)$ & $18 / 61(29.5 \%)$ & $5 / 19(26.3 \%)$ & 0.503 \\
\hline Hypertension (N, \%) & $46 / 63(73.0 \%)$ & $14 / 20(70.0 \%)$ & 0.501 \\
\hline Diabetes mellitus (N, \%) & $36 / 63(57.1 \%)$ & $11 / 20(55.0 \%)$ & 0.534 \\
\hline Dyslipidemia (N, \%) & $20 / 63(31.7 \%)$ & $5 / 20(25.0 \%)$ & 0.392 \\
\hline
\end{tabular}

aNormally distributed data are presented by mean and SD; bon-normally distributed data are presented by median and range; ${ }^{\circ}$ Coronary disease, previous stroke or peripheral artery disease. ${ }^{*} \mathrm{P}<0.05$ indicates statistically significant difference between unilateral and bilateral adenoma.

mass by an imaging workup of the abdomen, performed for the evaluation of unrelated diseases. At computed tomography (CT) all adrenal masses showed typical benign features: small size $(<60 \mathrm{~mm})$, homogeneous and well-circumscribed, CT attenuation $\leq 10$ Hounsfield units (HU) or contrast-enhanced washout CT within adenoma range [15, 16-18]. All patients repeated the CT 6 months after and no change in size or mass characteristics was observed.

None of the patients showed either signs or symptoms specific of cortisol excess or were medicated with drugs influencing cortisol and dexamethasone metabolism or cortisol secretion $[19,20]$. Patients with previous or current history of malignancy known to metastasize in the adrenal glands were excluded.

\section{Study protocol}

Patients with AI underwent a standardized diagnostic protocol, including a detailed clinical, biochemical and hormonal evaluation. Screening for hypercortisolism included the evaluation of 24-h excretion of urinary free cortisol (UFC), morning (MSC) and late night salivary cortisol (LNSC) and overnight low-dose dexamethasone suppression test (1-mg DST) with measurement of serum cortisol at 8 am the following morning.
In patients with serum cortisol $>1.8 \mu \mathrm{g} / \mathrm{dL}$ after 1 -mg DST, overt CS was subsequently excluded with basis on normal LNSC, UFC excretion, ACTH and 2-day low dose dexamethasone test.

The diagnosis of pheochromocytoma and primary hyperaldosteronism was excluded by determinations of plasma-free metanephrines 24-hour urinary metanephrines and catecholamines and plasma aldosterone/renin activity ratio (ARR) $[15$, $21,22]$.

\section{Group 2 (reference group (confirmed CS patients))}

The reference group included 50 patients with confirmed CS (47 cases of Cushing's disease (CD) and three cases of ectopic CS. CS diagnosis was stablished with basis on at least two of the following: the lack of cortisol suppression below $1.8 \mu \mathrm{g} /$ $\mathrm{dL}$ after the 1-mg DST, an elevated LNSC and elevated UFC levels (a mean of two collections). The diagnosis of CD was established in patients with normal or elevated serum ACTH levels and a high-dose dexamethasone test with $\geq 80 \%$ suppression of cortisol levels, an increase in ACTH of 50\% and plasma cortisol of $20 \%$ in response to corticotropin-releasing hormone $(\mathrm{CRH})$ stimulation test or a baseline central/peripheral ACTH ratio above 2 and after CRH stimulation above 3

Table 2. Comparative Results of Screening Tests for Hypercortisolism Between Patients With Al and Cushing Syndrome

\begin{tabular}{lllll} 
& Cutoff & Adrenal incidentaloma & Control group (Cushing syndrome) $^{\text {a }}$ & P \\
\hline & $\leq 1.8 \mu \mathrm{g} / \mathrm{dL}$ & $58 / 83(69.9)$ & 0 & $<0.001^{*}$ \\
1 -mg DST & $1.9-5.0 \mu \mathrm{g} / \mathrm{dL}$ & $22 / 83(26.5)$ & $6 / 36(16.7)$ & $30 / 36(83.3)$ \\
& $>5.0 \mu \mathrm{g} / \mathrm{dL}$ & $3 / 83(3.6)$ & $15 / 16(93.8)$ & $<0.001^{*}$ \\
LNSC & $>0.350 \mu \mathrm{g} / \mathrm{dL}$ & $17 / 83(20.5)$ & $35 / 41(85.4)$ & $<0.001^{*}$ \\
\hline
\end{tabular}

aData are presented in proportion and \%. ${ }^{*} \mathrm{P}<0.05$ indicates statistically significant difference between adrenal incidentaloma and the control group. 
in the inferior petrosal sinus sampling (IPSS). Ectopic CS was confirmed by IPSS, indicating a non-pituitary ACTH source.

\section{Assays}

Hormones were measured in-house with commercially available reagents. Late night saliva samples were collected between $11 \mathrm{pm}$ and midnight and morning saliva samples between 7 am and 8 am, using cotton swabs from Salivette ${ }^{\circledR}$ tubes (Sarstedt, Numbrecht, Germany). All patients received detailed and careful instructions on how to properly perform home sampling for LNSC. LNSC and serum cortisol were measured using an automated electrochemiluminescence immunoassay (Cobas e601, Roche Diagnostics, Mannheim, Germany). The crossreactivity with dexamethasone was negligible. UFC was measured using a chemiluminescent microparticle immunoassay (ARCHITECT i2000SR, Abbott).

Statistical analysis was performed with SPSS $($ Statistics V.22. Data are presented as proportions, means (SD), or, in the case of variables that did not conform to a normal distribution, median (range). For independent samples, two-way comparisons for proportions were performed by Chi-square test $\left(\chi^{2}\right)$ for categorical variables and Mann-Whitney $U$ test for continuous variables. Statistical significance was taken as two-tailed at the level of 0.05 . All phases of preparation for the study were in line with the ethical and deontological principles regarding data collection and statistical analysis. All patient clinical data were anonymized and analyzed by an independent reviewer. For this type of study formal consent is not required.

\section{Results}

Patients with AI were predominantly female (61.9\%), with a mean age of $66.2 \pm 12.5$ years. Most patients presented a unilateral adrenal mass $(75.9 \%)$, with a median size of 20.5 $\mathrm{mm}$ (range $8.0-53.0 \mathrm{~mm}$ ), and only in three patients the size was higher than $40 \mathrm{~mm}$ (3.6\%). Median BMI of AI patients was 27.8 (range 20.3 - 42.4), 28.8\% were obese, $72.3 \%$ had hypertension, $56.6 \%$ had type 2 diabetes mellitus, $30.1 \%$ had dyslipidemia and $17.5 \%$ had documented atherosclerotic cardiovascular disease. Other clinical and biochemical characteristics of patients with AI are presented in Table 1.

In the AI group, morning cortisol levels after 1-mg DST were $\leq 1.8 \mu \mathrm{g} / \mathrm{dL}$ in $58(69.9 \%)$ patients, between 1.9 and $5 \mu \mathrm{g} /$ $\mathrm{dL}$ in 22 patients $(26.5 \%)$ and $>5 \mu \mathrm{g} / \mathrm{dL}$ in three cases $(3.6 \%)$. LNSC was elevated $(>0.350 \mu \mathrm{g} / \mathrm{dL})$ in 17 patients $(20.5 \%)$ and all patients had normal UFC levels ( $\leq 172 \mathrm{~mol} / 24 \mathrm{~h}$ ) (Table 2$)$. In patients with bilateral adrenal incidentalomas, LNSC was more frequently elevated $(40.0 \%$ vs. $15.9 \%$; $\mathrm{P}<0.05)$. Patients without cortisol suppression $\leq 1.8 \mu \mathrm{g} / \mathrm{dL}$ after $1-\mathrm{mg}$ DST were more frequently hypertensive $(88.0 \%$ vs. $65.5 \%$; $\mathrm{P}<0.05)$ and dyslipidemic $(48.0 \%$ vs. $22.4 \%$; $<<0.05)$ (Table 3$)$.

The control group consisted of 50 patients with confirmed $\mathrm{CS}$, with a mean age of $53.6 \pm 16.0$ years and the majority were female $(76.0 \%)$. CS patients had significantly higher median levels of cortisol after 1-mg DST, LNSC and UFC $(\mathrm{P}<0.001)$

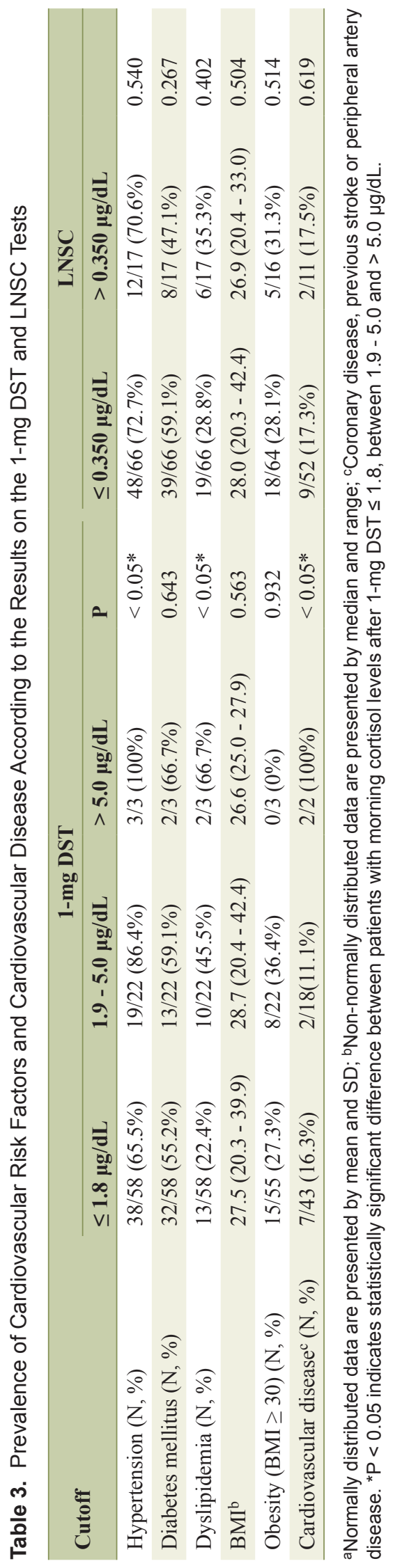


Table 4. Comparison of Demographic and Biochemical Characteristics Between Patients With Adrenal Incidentaloma and Cushing Syndrome

\begin{tabular}{llll} 
& Adrenal incidentaloma & Control group (Cushing syndrome) & P \\
\hline Age $($ years) & $66.2 \pm 12.6$ & $53.6 \pm 16.0$ & $<0.001 *$ \\
Gender $(\mathrm{N}, \%$ female) & $52(62.7 \%)$ & $38(76.0 \%)$ & 0.079 \\
Cortisol after 1-mg DST $(\mu \mathrm{g} / \mathrm{dL})^{\mathrm{b}}$ & $1.5(0.4-7.0)$ & $8.5(2.0-41.0)$ & $<0.001 *$ \\
MSC $(\mu \mathrm{g} / \mathrm{dL})^{\mathrm{b}}$ & $0.512(0.005-1.430)$ & $0.735(0.266-2.21)$ & 0.086 \\
LNSC $(\mu \mathrm{g} / \mathrm{dL})^{\mathrm{b}}$ & $0.224(0.005-1.140)$ & $0.779(0.192-9.890)$ & $<0.001 *$ \\
LNSC/MSC ratio & $0.36(0.49-4.23)$ & $0.89(0.49-1.92)$ & $<0.001^{\mathrm{b}}$ \\
UFC $(\mathrm{nmol} / 24 \mathrm{~h})^{\mathrm{b}}$ & $30.0(4.4-130.0)$ & $275.0(42.5-5,241.0)$ & $<0.001^{*}$ \\
\hline
\end{tabular}

aNormally distributed data are presented by mean and SD; bNon-normally distributed data are presented by median and range. * $\mathrm{P}<0.05$ indicates statistically significant difference between adrenal incidentaloma and the control group.

and a higher LNSC/MSC ratio $(\mathrm{P}<0.001)$ than patients with AI (Table 4). In this subgroup, all 36 patients who underwent 1-mg DST had cortisol levels $>1.8 \mu \mathrm{g} / \mathrm{dL}$ after 1 -mg DST, six of which (16.2\%) between 1.9 and $5 \mu \mathrm{g} / \mathrm{dL}$ and $30(83.3$ $\%)>5 \mu \mathrm{g} / \mathrm{dL}$; LNSC was elevated in $15(93.8 \%)$ of the 16 patients who underwent the test and the UFC was increased in $35(85.4 \%)$ of 41 patients tested (Table 2). The sensitivity, specificity, positive and negative predictive values and likelihood ratios for each one of the tests are presented in Table 5.

\section{Discussion}

The ideal diagnostic approach to a patient with an adrenal incidentaloma has been the subject of discussion over the last few decades. For several reasons, the diagnosis of SH is one of the biggest challenges for a clinician, especially in cases of mild hypercortisolism. First, cortisol secretion is a continuum with no clear separation from completely normal to increased levels, making it difficult to define cutoffs of indexes of cortisol secretion to most screening tests. Second, all currently available screening tests for the diagnosis of endogenous CS have limitations [23-26]. In order to standardize the clinical approach of these patients, the European Society of Endocrinology (ESE) has recently issued guidelines on the management of adrenal incidentalomas. The ESE panel recommends the use of the overnight 1-mg DST to exclude cortisol excess in all patients with AI, with basis on the simplicity of the test, the large evidence with its use and the physiological principle that in a patient with $\mathrm{SH}$ the mild adrenal cortisol secretion is not completely suppressed by a low dose of dexamethasone, but may not be high enough to raise total urinary cortisol secretion. Serum cortisol levels after 1-mg DST lower than $1.8 \mu \mathrm{g} / \mathrm{dL}$ are recommended as a diagnostic criterion for the exclusion of autonomous cortisol secretion, whereas levels between 1.9 and $5.0 \mu \mathrm{g} / \mathrm{dL}$ should be considered as evidence of "possible autonomous cortisol secretion" and cortisol levels above $5.0 \mu \mathrm{g} /$ $\mathrm{dL}$ should be taken as evidence of "autonomous cortisol secretion". In the cases with serum cortisol levels after 1-mg DST $\geq 1.8 \mu \mathrm{g} / \mathrm{dL}$, the majority of the ESE Panel members preferred additional tests to better judge the degree of hypercortisolism, such as ACTH, $24 \mathrm{~h} \mathrm{UFC} \mathrm{(and/or} \mathrm{LNSC)} \mathrm{and} \mathrm{repetition} \mathrm{of} \mathrm{the}$ 1 -mg DST in 6 to 12 months [15].

Our findings confirm that adrenal autonomy is best assessed by the overnight 1-mg DST and the use of the lowest threshold proposed by ESE (a cortisol level $\leq 1.8 \mu \mathrm{g} / \mathrm{dL}$ ) reaches the highest sensitivity (100\%) to the diagnosis of CS. However, this cutoff exhibits a low specificity (69.9\%) which emphasizes the need for further complementary tests to rule out false positive results. As expected, when the highest cutoff (a cortisol level $\leq 5.0 \mu \mathrm{g} / \mathrm{dL}$ ) was considered the sensitivity was lower $(83.3 \%)$ but the specificity increased to $96.4 \%$. Previous studies have showed similar results, with reported sensitivities ranging from 75 to $100 \%$ and specificities from 67 to $71 \%$ when the lowest cutoffs were used $(\leq 1.8 \mu \mathrm{g} / \mathrm{dL})$ and if the highest cutoffs $(\leq 5.0 \mu \mathrm{g} / \mathrm{dL})$ were considered the sensitivity decreased to $44-58 \%$ and specificity increased to $83-100 \%$ [27-36]. These data suggest that cortisol levels after 1-mg DST $>5.0 \mu \mathrm{g} / \mathrm{dL}$ are effective to detect $\mathrm{SH}$ in patients with $\mathrm{AI}$ and levels $\leq 1.8 \mu \mathrm{g} / \mathrm{dL}$ are precise to rule out this diagnosis.

On the other hand, in this study, the UFC presented a maximum specificity (100\%) for the diagnosis of SC but its

Table 5. Performance of Screening Tests for Hypercortisolism in a Group of Patients With Adrenal Incidentaloma

\begin{tabular}{llllllll}
\hline Test & Cutoff & SE $(\%)$ & SP $(\%)$ & PPV (\%) & NPV (\%) & LR $^{\text {pos }}$ & LR $^{\text {neg }}$ \\
\hline 1-mg DST & $1.8 \mu \mathrm{g} / \mathrm{dL}$ & 100 & 69.9 & 59.0 & 100 & 3.32 & - \\
& $5.0 \mu \mathrm{g} / \mathrm{dL}$ & 83.3 & 96.4 & 90.0 & 93.0 & 23.1 & 0.173 \\
LNSC & $0.350 \mu \mathrm{g} / \mathrm{dL}$ & 93.8 & 79.5 & 46.9 & 98.5 & 4.58 & 0.079 \\
UFC & $172 \mathrm{nmol} / 24 \mathrm{~h}$ & 85.4 & 100 & 100 & 93.3 & - & 0.146 \\
\hline
\end{tabular}

SE: sensitivity; SP: specificity; PPV: positive predictive value; NPV: negative predictive value; LR pos: positive likelihood ratio; LR ${ }^{\text {neg: }}$ negative likelihood ratio. $L R^{\text {pos }}$ cannot be calculated if $S P=100 \%$ and $L R^{\text {neg }}$ cannot be calculated if $S E=100 \%$. 
unsatisfactory sensitivity $(85.4 \%)$ makes it unreliable for detecting subtle increases in cortisol secretion. Data previously reported from other series confirmed its lack of sensitivity for the detection of subclinical disorders of the HPA axis $[28,37$, 38]. Therefore, UFC is not an adequate screening test for $\mathrm{SH}$, but it can be useful in combination with other tests to increase the specificity.

Regarding the role of salivary cortisol in the screening of $\mathrm{CS}$, in this series of patients LNSC levels and LNSC/MSC ratio were significantly higher in patients CS compare to patients with $\mathrm{AI}$ in whom CS was subsequently excluded by detailed clinical, biochemical and hormonal testing. The cutoff value validated by our laboratory $(\leq 0.350 \mu \mathrm{g} / \mathrm{dL})$ presented a sensitivity of $93.8 \%$ and a specificity of $79.5 \%$ to the diagnosis of CS. Several authors showed an altered circadian cortisol secretion rhythm in AI patients with high midnight plasma and salivary cortisol levels [39-43]. In a meta-analysis of seven studies the estimated sensitivity and specificity of LNSC for the diagnosis of CS was $92 \%$ and $96 \%$, respectively [44].

In this cohort of patients with AI, we found a high prevalence of hypertension (72.3\%), type 2 diabetes mellitus (56.6\%), dyslipidemia $(30.1 \%)$ and obesity $(28.8 \%)$. AI patients with cortisol levels after $1-\mathrm{mg}$ DST $\geq 1.8 \mu \mathrm{g} / \mathrm{dL}$ had a significantly higher prevalence of hypertension, dyslipidemia and established cardiovascular disease. Reports from different research groups have consistently demonstrated an association between cortisol excess, hypertension, impairment of glucose metabolism, dyslipidemia and an increased risk of cardiovascular diseases [4, 12, 45-50]. These data support the concept that although $\mathrm{SH}$ is not associated with the typical clinical manifestations of overt cortisol excess, this condition may lead to long-term consequences of cortisol excess and an increased rate of several metabolic and cardiovascular co-morbidities, such as hypertension, impaired glucose metabolism and increased visceral fat.

\section{Conclusions}

The 1-mg DST at its lowest threshold $(\leq 1.8 \mu \mathrm{g} / \mathrm{dL})$ shows a high sensitivity to rule out CS in patients with adrenal incidentaloma, however, its low specificity addresses the need for additional testing after a positive screening. Due to its high specificity, we suggest combine use of UFC to reduce the number of false-positive test results.

\section{Conflict of Interest}

The authors declare that they have no conflict of interest.

\section{References}

1. Chidiac RM, Aron DC. Incidentalomas. A disease of modern technology. Endocrinol Metab Clin North Am. 1997;26(1):233-253.

2. Kloos RT, Korobkin M, Thompson NW, Francis IR, Shapiro B, Gross MD. Incidentally discovered adrenal masses.
In: Endocrine Neoplasms. Springer. 1997; pp 263-292.

3. Mansmann G, Lau J, Balk E, Rothberg M, Miyachi Y, Bornstein SR. The clinically inapparent adrenal mass: update in diagnosis and management. Endocr Rev. 2004;25(2):309-340.

4. Rossi R, Tauchmanova L, Luciano A, Di Martino M, Battista C, Del Viscovo L, Nuzzo V, et al. Subclinical Cushing's syndrome in patients with adrenal incidentaloma: clinical and biochemical features. J Clin Endocrinol Metab. 2000;85(4):1440-1448.

5. Terzolo M, Pia A, Ali A, Osella G, Reimondo G, Bovio S, Daffara F, et al. Adrenal incidentaloma: a new cause of the metabolic syndrome? J Clin Endocrinol Metab. 2002;87(3):998-1003.

6. Chiodini I. Clinical review: Diagnosis and treatment of subclinical hypercortisolism. J Clin Endocrinol Metab. 2011;96(5):1223-1236.

7. Young WF, Jr. Clinical practice. The incidentally discovered adrenal mass. N Engl J Med. 2007;356(6):601-610.

8. Thompson GB, Young WF, Jr. Adrenal incidentaloma. Curr Opin Oncol. 2003;15(1):84-90.

9. Peppa M, Boutati E, Koliaki C, Papaefstathiou N, Garoflos E, Economopoulos T, Hadjidakis D, et al. Insulin resistance and metabolic syndrome in patients with nonfunctioning adrenal incidentalomas: a cause-effect relationship? Metabolism. 2010;59(10):1435-1441.

10. Young WF, Jr. Management approaches to adrenal incidentalomas. A view from Rochester, Minnesota. Endocrinol Metab Clin North Am. 2000;29(1):159-185, x.

11. Terzolo M, Bovio S, Reimondo G, Pia A, Osella G, Borretta G, Angeli A. Subclinical Cushing's syndrome in adrenal incidentalomas. Endocrinol Metab Clin North Am. 2005;34(2):423-439, x.

12. Olsen H, Nordenstrom E, Bergenfelz A, Nyman U, Valdemarsson S, Palmqvist E. Subclinical hypercortisolism and CT appearance in adrenal incidentalomas: a multicenter study from Southern Sweden. Endocrine. 2012;42(1):164-173.

13. Kim J, Bae KH, Choi YK, Jeong JY, Park KG, Kim JG, Lee IK. Clinical characteristics for 348 patients with adrenal incidentaloma. Endocrinol Metab (Seoul). 2013;28(1):20-25.

14. Cho YY, Suh S, Joung JY, Jeong H, Je D, Yoo H, Park TK, et al. Clinical characteristics and follow-up of Korean patients with adrenal incidentalomas. Korean J Intern Med. 2013;28(5):557-564.

15. Fassnacht M, Arlt W, Bancos I, Dralle H, Newell-Price J, Sahdev A, Tabarin A, et al. Management of adrenal incidentalomas: European Society of Endocrinology Clinical Practice Guideline in collaboration with the European Network for the Study of Adrenal Tumors. Eur J Endocrinol. 2016;175(2):G1-G34.

16. Zhang HM, Perrier ND, Grubbs EG, Sircar K, Ye ZX, Lee JE, Ng CS. CT features and quantification of the characteristics of adrenocortical carcinomas on unenhanced and contrast-enhanced studies. Clin Radiol. 2012;67(1):3846.

17. Schieda N, Siegelman ES. Update on CT and MRI of Adrenal Nodules. AJR Am J Roentgenol. 2017;208(6):1206- 
1217.

18. Graham DJ, McHenry CR. The adrenal incidentaloma: guidelines for evaluation and recommendations for management. Surg Oncol Clin N Am. 1998;7(4):749-764.

19. Nieman LK, Biller BM, Findling JW, Newell-Price J, Savage MO, Stewart PM, Montori VM. The diagnosis of Cushing's syndrome: an Endocrine Society Clinical Practice Guideline. J Clin Endocrinol Metab. 2008;93(5):1526-1540.

20. Nieman LK. Cushing's syndrome: update on signs, symptoms and biochemical screening. Eur J Endocrinol. 2015;173(4):M33-38.

21. Lenders JW, Duh QY, Eisenhofer G, Gimenez-Roqueplo AP, Grebe SK, Murad MH, Naruse M, et al. Pheochromocytoma and paraganglioma: an endocrine society clinical practice guideline. J Clin Endocrinol Metab. 2014;99(6):1915-1942.

22. Funder JW, Carey RM, Mantero F, Murad MH, Reincke M, Shibata H, Stowasser M, et al. The Management of Primary Aldosteronism: Case Detection, Diagnosis, and Treatment: An Endocrine Society Clinical Practice Guideline. J Clin Endocrinol Metab. 2016;101(5):1889-1916.

23. Nieman LK. Difficulty in the diagnosis of Cushing disease. Nat Clin Pract Endocrinol Metab. 2006;2(1):53-57; quiz following 57.

24. Grumbach MM, Biller BM, Braunstein GD, Campbell KK, Carney JA, Godley PA, Harris EL, et al. Management of the clinically inapparent adrenal mass ("incidentaloma"). Ann Intern Med. 2003;138(5):424-429.

25. Tsagarakis S, Vassiliadi D, Thalassinos N. Endogenous subclinical hypercortisolism: Diagnostic uncertainties and clinical implications. J Endocrinol Invest. 2006;29(5):471-482.

26. Valassi E, Swearingen B, Lee H, Nachtigall LB, Donoho DA, Klibanski A, Biller BM. Concomitant medication use can confound interpretation of the combined dexamethasone-corticotropin releasing hormone test in Cushing's syndrome. J Clin Endocrinol Metab. 2009;94(12):48514859.

27. Ceccato F, Antonelli G, Frigo AC, Regazzo D, Plebani M, Boscaro M, Scaroni C. First-line screening tests for Cushing's syndrome in patients with adrenal incidentaloma: the role of urinary free cortisol measured by LC-MS/MS. J Endocrinol Invest. 2017;40(7):753-760.

28. Valli N, Catargi B, Ronci N, Vergnot V, Leccia F, Ferriere JM, Chene G, et al. Biochemical screening for subclinical cortisol-secreting adenomas amongst adrenal incidentalomas. Eur J Endocrinol. 2001;144(4):401-408.

29. Bulow B, Ahren B, Swedish Research Council Study Group of Endocrine Abdominal T. Adrenal incidentaloma - experience of a standardized diagnostic programme in the Swedish prospective study. J Intern Med. 2002;252(3):239-246.

30. Libe R, Dall'Asta C, Barbetta L, Baccarelli A, BeckPeccoz P, Ambrosi B. Long-term follow-up study of patients with adrenal incidentalomas. Eur J Endocrinol. 2002;147(4):489-494.

31. Emral R, Uysal AR, Asik M, Gullu S, Corapcioglu D, Tonyukuk V, Erdogan G. Prevalence of subclinical Cush- ing's syndrome in 70 patients with adrenal incidentaloma: clinical, biochemical and surgical outcomes. Endocr J. 2003;50(4):399-408.

32. Katabami T, Obi R, Shirai N, Naito S, Saito N. Discrepancies in results of low-and high-dose dexamethasone suppression tests for diagnosing preclinical Cushing's syndrome. Endocr J. 2005;52(4):463-469.

33. Morelli V, Masserini B, Salcuni AS, Eller-Vainicher C, Savoca C, Viti R, Coletti F, et al. Subclinical hypercortisolism: correlation between biochemical diagnostic criteria and clinical aspects. Clin Endocrinol (Oxf). 2010;73(2):161-166.

34. Eller-Vainicher C, Morelli V, Salcuni AS, Battista C, Torlontano M, Coletti F, Iorio L, et al. Accuracy of several parameters of hypothalamic-pituitary-adrenal axis activity in predicting before surgery the metabolic effects of the removal of an adrenal incidentaloma. Eur J Endocrinol. 2010;163(6):925-935.

35. Stewart PM. Is subclinical Cushing's syndrome an entity or a statistical fallout from diagnostic testing? Consensus surrounding the diagnosis is required before optimal treatment can be defined. Oxford University Press. 2010.

36. Barzon L, Fallo F, Sonino N, Boscaro M. Overnight dexamethasone suppression of cortisol is associated with radiocholesterol uptake patterns in adrenal incidentalomas. Eur J Endocrinol. 2001;145(2):223-224.

37. Reincke M. Subclinical Cushing's syndrome. Endocrinol Metab Clin North Am. 2000;29(1):43-56.

38. Lavoie H, Lacroix A. Partially autonomous cortisol secretion by incidentally discovered adrenal adenomas. Trends Endocrinol Metab. 1995;6(6):191-197.

39. Beko G, Varga I, Glaz E, Sereg M, Feldman K, Toth M, Racz K, et al. Cutoff values of midnight salivary cortisol for the diagnosis of overt hypercortisolism are highly influenced by methods. Clin Chim Acta. 2010;411(56):364-367.

40. Baid SK, Rubino D, Sinaii N, Ramsey S, Frank A, Nieman LK. Specificity of screening tests for Cushing's syndrome in an overweight and obese population. J Clin Endocrinol Metab. 2009;94(10):3857-3864.

41. Doi M, Sekizawa N, Tani Y, Tsuchiya K, Kouyama R, Tateno $\mathrm{T}$, Izumiyama $\mathrm{H}$, et al. Late-night salivary cortisol as a screening test for the diagnosis of Cushing's syndrome in Japan. Endocr J. 2008;55(1):121-126.

42. Viardot A, Huber P, Puder JJ, Zulewski H, Keller U, Muller B. Reproducibility of nighttime salivary cortisol and its use in the diagnosis of hypercortisolism compared with urinary free cortisol and overnight dexamethasone suppression test. J Clin Endocrinol Metab. 2005;90(10):5730-5736.

43. Putignano P, Toja P, Dubini A, Pecori Giraldi F, Corsello SM, Cavagnini F. Midnight salivary cortisol versus urinary free and midnight serum cortisol as screening tests for Cushing's syndrome. J Clin Endocrinol Metab. 2003;88(9):4153-4157.

44. Carroll T, Raff H, Findling JW. Late-night salivary cortisol for the diagnosis of Cushing syndrome: a meta-analysis. Endocr Pract. 2009;15(4):335-342.

45. Mantero F, Terzolo M, Arnaldi G, Osella G, Masini AM, 
Ali A, Giovagnetti M, et al. A survey on adrenal incidentaloma in Italy. Study Group on Adrenal Tumors of the Italian Society of Endocrinology. J Clin Endocrinol Metab. 2000;85(2):637-644.

46. Di Dalmazi G, Vicennati V, Rinaldi E, Morselli-Labate AM, Giampalma E, Mosconi C, Pagotto U, et al. Progressively increased patterns of subclinical cortisol hypersecretion in adrenal incidentalomas differently predict major metabolic and cardiovascular outcomes: a large crosssectional study. Eur J Endocrinol. 2012;166(4):669-677.

47. Tauchmanova L, Rossi R, Biondi B, Pulcrano M, Nuzzo V, Palmieri EA, Fazio S, et al. Patients with subclinical Cushing's syndrome due to adrenal adenoma have increased cardiovascular risk. J Clin Endocrinol Metab. 2002;87(11):4872-4878.

48. Di Dalmazi G, Vicennati V, Garelli S, Casadio E, Rinaldi
E, Giampalma E, Mosconi C, et al. Cardiovascular events and mortality in patients with adrenal incidentalomas that are either non-secreting or associated with intermediate phenotype or subclinical Cushing's syndrome: a 15year retrospective study. Lancet Diabetes Endocrinol. 2014;2(5):396-405.

49. Erbil Y, Ademoglu E, Ozbey N, Barbaros U, Yanik BT, Salmaslioglu A, Bozbora A, et al. Evaluation of the cardiovascular risk in patients with subclinical Cushing syndrome before and after surgery. World J Surg. 2006;30(9):1665-1671.

50. Kim BY, Chun AR, Kim KJ, Jung CH, Kang SK, Mok JO, $\mathrm{Kim} \mathrm{CH}$. Clinical characteristics and metabolic features of patients with adrenal incidentalomas with or without subclinical Cushing's syndrome. Endocrinol Metab (Seoul). 2014;29(4):457-463. 